\section{Genetic Relatedness in Prunus Genus Revealed by Inter-simple Sequence Repeat Markers}

\author{
Kadir Uğurtan Yilmaz \\ Fruit Research Institute, Ministry of Agriculture, Malatya, Turkey
}

\author{
Sezai Ercişli \\ Department of Horticulture, Faculty of Agriculture, University of Ataturk, \\ Erzurum, Turkey
}

Bayram Murat Asma
Apricot Research Center, University of Inonu, Malatya, Turkey

Yıldız Doğan and Salih Kafkas ${ }^{1}$

Department of Horticulture, Faculty of Agriculture, University of Cukurova, Adana, Turkey

Additional index words. Prunus, ISSR, Prunophora, Armeniaca, plumcot, Cerasus

\begin{abstract}
Inter-simple sequence repeat (ISSR) markers were used to study the genetic diversity and phylogenetic relationships among 16 genotypes from subgenus Prunus (six genotypes from section Prunophora, seven genotypes from section Armeniaca and two plumcot genotypes, and one genotype from subgenus Cerasus) in Prunus genus. From the polymerase chain reaction amplifications with 20 ISSR primers showing polymorphism among subgenera and sections, 180 polymorphic ISSR bands were detected and polymorphism ratio ranged from $57 \%$ to $100 \%$. Based on the unweighted pair group method with arithmetic mean (UPGMA) analysis and principal coordinate analysis (PCoA) using the Jaccard coefficient, a dendrogram and three-dimensional plot were constructed including genotypes in Prunus genus. Two main groups formed in the dendrogram; one of them (Cluster I) included Cerasus, whereas Cluster II included Prunus. Cluster II also divided into three subgroups, including sections Prunophora, Armeniaca, and plumcot. Both UPGMA and the PCoA demonstrated that Armeniaca genotypes had lower genetic variation and plumcot genotypes are closer to the plums than the apricots. The ISSR-based phylogeny was generally consistent with Prunus taxonomy based on molecular evidence, suggesting the applicability of ISSR analysis for genotypic and phylogenetic studies in Prunus genus.
\end{abstract}

The genus Prunus comprises five subgenera: Prunus, Amygdalus, Cerasus, Padus, and Laurocerasus and includes $\approx 200$ species, which are economically important as sources of fruits, nuts, oil, timber, and ornamentals (Reynders and Salesses, 1990). The subgenus Prunus includes section Prunophora comprising plums and section Armeniaca containing apricots. Each of these sections is considered to be a single gene pool (Watkins, 1976). Plums are adapted to the cooler temperate regions, whereas apricots are grown in warmer temperature regions of the world. Plums belonging to subgenus Prunophora are considered to be important for Prunus evolution because they include more than 20 species with abundant variation in their morphology. Differences in genetic diversity between plums and apricots are much influenced by the self-(in)compatibility phenotype of these species (Halasz

Received for publication 2 Sept. 2008. Accepted for publication 1 Nov. 2008.

${ }^{1}$ To whom reprint requests should be addressed; e-mailskafkas@cu.edu.tr. of chromosomes. Most cultivated apricots belong to the species $P$. armeniaca that originated in Central Asia where it has been cultivated for millennia and from where it was later disseminated both eastward and westward (Hormaza, 2002; Maghuly et al., 2005). The subgenus Cerasus comprising diploid sweet cherry and tetraploid tart cherry constitutes a distinct group distantly related to the other two subgenera, Amygdalus and Prunus (Reynders and Salesses, 1990).

Breeding barriers exist among subgenera possessing different ploidy levels, even within the same subgenus, but artificial or natural hybrids are generally successful, in particular between Prunophora (plums) and Armeniaca (apricots), when both parents have the same ploidy level (Okie and Weinberger, 1996). The subgenera Padus and Laurocerasus are more isolated within the genus Prunus.

The traditional taxonomic classification within the genus Prunus is mainly based on fruit morphology and has been controversial (Aradhya et al., 2004). This approach is also subject to environmental influences, mainly as a result of the long generation time and large size of the trees. Trees are also influenced by agricultural factors like rootstocks or pruning. Therefore, precise characterization and identification of species within the Prunus subgenus are important to recognize gene pools, to identify pitfalls in germplasm collections, and to develop effective conservation and management strategies. New methods based on molecular evaluations may provide further insight into the genetic structure and differentiation within Prunus (Aradhya et al., 2004). Genetic characterization of diversity and relationships at both inter- and intraspecific levels in the genus, Prunus, is limited to a few molecular phylogenetic studies using ITS and chloroplast trnL-trnF spacer sequence variation (Bortiri et al., 2001) and amplified fragment length polymorphism (Aradhya et al., 2004).

Choice of the marker system to use for a particular application depends on its ease of use and the particular objectives of the investigation (Rafalski et al., 1996). Recently, inter-simple sequence repeat (ISSR) markers have emerged as an alternative system with the reliability and several advantages over random amplified polymorphic DNA (RAPD), amplified fragment length polymorphism (AFLP), and simple sequence repeat (SSR). ISSR is a simple and quick method that combines most of the advantages of SSRs and AFLPs to the universality of RAPDs. The major limitations of RAPD, AFLP, and SSR methods are low reproducibility of RAPD and high cost of AFLP while flanking sequences have to be known to develop species-specific primers for SSR polymorphism. ISSR overcomes most of these limitations (Reddy et al., 2002). The main disadvantages of ISSR are the dominant nature and lower multiplex ratio. This method has been used in several fruit crops such as olive (Terzopoulos et al., 2005), pistachio (Kafkas et al., 2006), plum (Lisek 
et al., 2007), citrus (Shahsavar et al., 2007), and mulberry (Vijayan and Chatterjee, 2003; Vijayan et al., 2006a, 2006b) for the purposes of cultivar identification, germplasm characterization, natural population diversity evaluation, phylogenetic relationship analysis, genetic linkage mapping, and marker-assisted selection. The ISSR was also applied in genus Prunus (Goulao et al., 2001; Liu et al., 2007) and showed higher reproducibility and percentage of polymorphism than AFLP (Goulao et al., 2001). In addition, Turkish Prunus genotypes have only been characterized by morphological data so far and, in other words, no comparative studies on the molecular diversity among subgenera and sections in Turkish Prunus had been done. Therefore, in the present study, we used ISSR markers for fingerprinting a set of Prunus and Cerasus genotypes within genus Prunus.

\section{Materials and Methods}

Plant materials. For molecular analysis, totally 16 genotypes from genus Prunus (six genotypes from section Prunophora, seven genotypes from section Armeniaca and two plumcot genotypes, and one genotype from subgenus Cerasus) were used (Table 1). The genotypes were found together in a national germplasm collection at the Fruit Research Institute of Ministry of Agriculture in the Malatya province of Turkey.

DNA extraction and polymerase chain reaction procedure. Genomic DNA was extracted from leaf tissue by the CTAB method of Doyle and Doyle (1987) with minor modifications (Kafkas et al., 2005). Concentration of extracted DNA was estimated by comparing band intensity with $\lambda$ DNA of known concentrations after $0.8 \%$ agarose gel electrophoresis and ethidium bromide staining. DNA was diluted to 5 ng. $\mu \mathrm{L}^{-1}$ for ISSR reactions.

Polymerase chain reaction (PCR) mixtures had a total volume of $25 \mu \mathrm{L}$ containing $20 \mathrm{ng}$ of DNA template; $0.2 \mu \mathrm{M}$ primer; 100 $\mu \mathrm{M}$ each of dATP, dGTP, dCTP and dTTP; 1 unit of Taq DNA polymerase; $2 \mathrm{~mm} \mathrm{MgCI}_{2}$; $75 \mathrm{~mm}$ Tris- $\mathrm{HCl}$; $\mathrm{pH} 8.8,20 \mathrm{~mm}\left(\mathrm{NH}_{4}\right)_{2} \mathrm{SO}_{4}$; and $0.01 \%$ Tween 20. PCR amplifications

Table 1. Cultivars/genotypes of Prunus assayed with intersimple sequence repeat markers in the present study.

\begin{tabular}{rllll}
\hline No. & Genotype name & Subgenus & Section & Species \\
\hline 1 & Stanley & Prunus & Prunophora & P. domestica \\
2 & Giant & Prunus & Prunophora & P. domestica \\
3 & Canerigi & Prunus & Prunophora & P. cerasifera \\
4 & Papaz & Prunus & Prunophora & P. cerasifera \\
5 & Burmosa & Prunus & Prunophora & P. salicina \\
6 & Methley & Prunus & Prunophora & P. salicina \\
7 & Sakit 2 & Prunus & Armeniaca & A. vulgaris \\
8 & Aprikoz & Prunus & Armeniaca & A. vulgaris \\
9 & Cataloglu & Prunus & Armeniaca & A. vulgaris \\
10 & Hacihaliloglu & Prunus & Armeniaca & A. vulgaris \\
11 & Kabaasi & Prunus & Armeniaca & A. vulgaris \\
12 & Zerdalino1 & Prunus & Armeniaca & A. vulgaris \\
13 & Ordubat & Prunus & Armeniaca & A. vulgaris \\
14 & Inceazerigi & Prunus & Plumcot \\
15 & Kayisierigi & Prunus & Plumcot \\
16 & Dagerigi & Prunus & Cerasus & C. prostrata \\
\hline
\end{tabular}

were performed in a gradient thermal cycler (Eppendorf, Hamburg, Germany) with the following temperature profile: a predenaturation step of $3 \mathrm{~min}$ at $94{ }^{\circ} \mathrm{C}$ followed by 40 cycles of denaturation at $94{ }^{\circ} \mathrm{C}$ for $60 \mathrm{~s}$; annealing at 48 to $54{ }^{\circ} \mathrm{C}$ (depending on primer) for $60 \mathrm{~s}$; and extension at $72{ }^{\circ} \mathrm{C}$ for 120 s. A final extension was allowed for 7 min at $72{ }^{\circ} \mathrm{C}$. ISSR amplification products were analyzed by gel electrophoresis in $1.8 \%$ agarose in $1 \times$ TBE buffer, stained with ethidium bromide, and photographed under ultraviolet light.

Initially, 60 ISSR primers [University of British Columbia, Vancouver, Canada (set \#9)] were tested with six Prunus genotypes for PCR amplification. Based on assuming the maximum number of reproducible and distinctly scorable polymorphic bands, 20 ISSR primers were selected for the characterization of 16 Prunus genotypes. The annealing temperatures of ISSR primers determined by Kafkas et al. (2006) were used, and they are given in Table 1 with their sequences.

Data analysis. The ability of the most informative primer pairs to differentiate between the genotypes was assessed by calculating their resolving power (Rp) according to Prevost and Wilkinson (1999) using the formula $\mathrm{Rp}=\sum \mathrm{Ib}$, where $\mathrm{Ib}=1-$ $(2 \mathrm{x}|0.5-\mathrm{p}|)$, and $\mathrm{p}$ is the proportion of the 16 genotypes containing the I band. The polymorphism information content (PIC) of each marker was calculated using PIC $=1-$ $\sum \mathrm{Pi}^{2}$ where $\mathrm{Pi}$ is the band frequency of the $\mathrm{i}^{\text {th }}$ allele (Smith et al., 1997). Jaccard's similarity coefficients (Sneath and Sokal, 1973) were calculated for all pairwise comparisons among the 16 Prunus genotypes.

Two dendrograms were generated using NTSYSpc version 2.11V (Exeter Software, Setauket, NY) (Rohlf, 2004): unweighted pair group method of arithmetic average cluster analysis (UPGMA) and principal coordinate analyze (PCoA) based on the total number of amplified ISSR fragments. In PCoA, the genotypes were plotted on first three dimensions using the G3D procedure of the SAS program (SAS Institute Inc., 1990). For the first dendrogram, the bootstrap values were calculated with 1000 replicates using PAUP software (Swofford, 1998). The representativeness of the dendrogram was evaluated by estimating cophenetic correlation for the dendrogram and comparing it with the similarity matrix using Mantel's matrix correspondence test (Mantel, 1967). The result of this test is a cophenetic correlation coefficient, $r$, indicating how well the dendrogram represents similarity data.

\section{Results and Discussion}

Inter-simple sequence repeat polymorphism in Prunus. The results of ISSR fingerprinting of 16 Prunus genotypes using 20 primers are given in Table 2. From prescreening assays with six Prunus genotypes using 60 ISSR primers, 20 ISSR markers generated bright amplification products and polymorphisms and were used in further analysis. A total of 196 reliable fragments was obtained from 20 ISSR primers. The number of fragments per primer ranged from 5 to 17 with the average number of bands per primer being 9.8. Among the total bands, 180 fragments were polymorphic with the average of $89 \%$ polymorphism. The average number of polymorphic bands per primer was 9.0 (Table 2). According to Cao et al. (2000), 50 polymorphic bands (loci) are sufficient for a satisfactory classification and discrimination. Some polymorphic bands produced by ISSR primers seemed to be unique. If these bands are tested in an adequate number of Prunus genotypes in the future, the patterns can be used to distinguish different subgenera, sections, and also cultivars or genotypes within the sections in Prunus genus. Previously, using 27 ISSR primers for cultivar identifications in Prunophora section, 72 polymorphic fragments were obtained (Lisek et al., 2007) indicating that genetic diversity of Prunophora genotypes is high and confirming the suitability of ISSR for the diversification of Prunophora genotypes. It was also previously shown that ISSR markers have great potential to identify and establish phenetic relationships among plum cultivars (Goulao et al., 2001).

Genetic relationships within and among sections and subgenera. A dendrogram was obtained by UPGMA method using the total number of amplified ISSR fragments and consisted of two main well-supported distinct clusters corresponding to the two subgenera Cerasus (Cluster I) and Prunus (Cluster II; Fig. 1). The cv. Dagerigi belongs to subgenus Cerasus formed alone like an outgroup into Cluster I. The Cluster II was divided into three subgroups (Prunophora, Armeniaca, and plumcot). Within Cluster II, there was evidence for differentiation within and among sections or subgroups. In addition, several significant groups within sections, particularly in Prunophora, are related to the ploidy level and geographic origin of the genotypes (Fig. 1). In the dendrogram, Prunophora included diploid and hexaploid plum genotypes and Armeniaca included only diploid apricot genotypes (Fig. 1). Subgroup 
Table 2. Sequence of intersimple sequence repeat (ISSR) primers, annealing temperatures, number of total and polymorphic bands, percentage of polymorphism, polymorphism information content, and resolving power in the DNA fingerprinting of 16 genotypes from Prunus genus sampled from Turkey.

\begin{tabular}{|c|c|c|c|c|c|c|c|}
\hline $\begin{array}{l}\text { ISSR } \\
\text { primers }\end{array}$ & $\begin{array}{c}\text { Sequence } \\
\left(5^{\prime}-3^{\prime}\right)\end{array}$ & $\begin{array}{l}\text { Annealing } \\
\text { temp. }\left({ }^{\circ} \mathrm{C}\right)\end{array}$ & $\begin{array}{c}\text { Total } \\
\text { bands (no.) }\end{array}$ & $\begin{array}{l}\text { Polymorphic } \\
\text { bands (no.) }\end{array}$ & $\begin{array}{c}\text { Polymorphism } \\
(\%)\end{array}$ & $\begin{array}{c}\text { Resolving } \\
\text { power }\end{array}$ & $\begin{array}{c}\text { Polymorphism } \\
\text { information content }\end{array}$ \\
\hline $\mathrm{BC} 807$ & $(\mathrm{AG})_{8} \mathrm{~T}$ & 50 & 8 & 7 & 88 & 1.089 & 0.674 \\
\hline BC 812 & $(\mathrm{GA})_{8} \mathrm{~A}$ & 50 & 12 & 11 & 92 & 0.670 & 0.853 \\
\hline BC814 & $(\mathrm{CT})_{8} \mathrm{~A}$ & 50 & 14 & 13 & 93 & 0.760 & 0.817 \\
\hline BC 817 & $(\mathrm{CA})_{8} \mathrm{~A}$ & 50 & 11 & 11 & 100 & 0.841 & 0.754 \\
\hline BC 818 & $(\mathrm{CA})_{8} \mathrm{G}$ & 52 & 8 & 8 & 100 & 0.641 & 0.864 \\
\hline BC 825 & $(\mathrm{AC})_{8} \mathrm{~T}$ & 50 & 15 & 15 & 100 & 0.833 & 0.751 \\
\hline $\mathrm{BC} 840$ & $(\mathrm{GA})_{8} \mathrm{YT}$ & 52 & 8 & 7 & 88 & 0.964 & 0.695 \\
\hline BC 841 & $(\mathrm{GA})_{8} \mathrm{YC}$ & 54 & 9 & 8 & 89 & 0.828 & 0.742 \\
\hline BC 843 & $(\mathrm{CT})_{8} \mathrm{RA}$ & 52 & 6 & 6 & 100 & 0.792 & 0.708 \\
\hline BC847 & $(\mathrm{CA})_{8} \mathrm{RC}$ & 52 & 7 & 4 & 57 & 0.406 & 0.938 \\
\hline BC 868 & $(\mathrm{GAA})_{6}$ & 48 & 9 & 9 & 100 & 0.847 & 0.733 \\
\hline BC873 & $(\mathrm{GACA})_{4}$ & 48 & 17 & 17 & 100 & 0.721 & 0.838 \\
\hline Mean & & & 9.8 & 9.0 & 89 & 0.829 & 0.742 \\
\hline
\end{tabular}

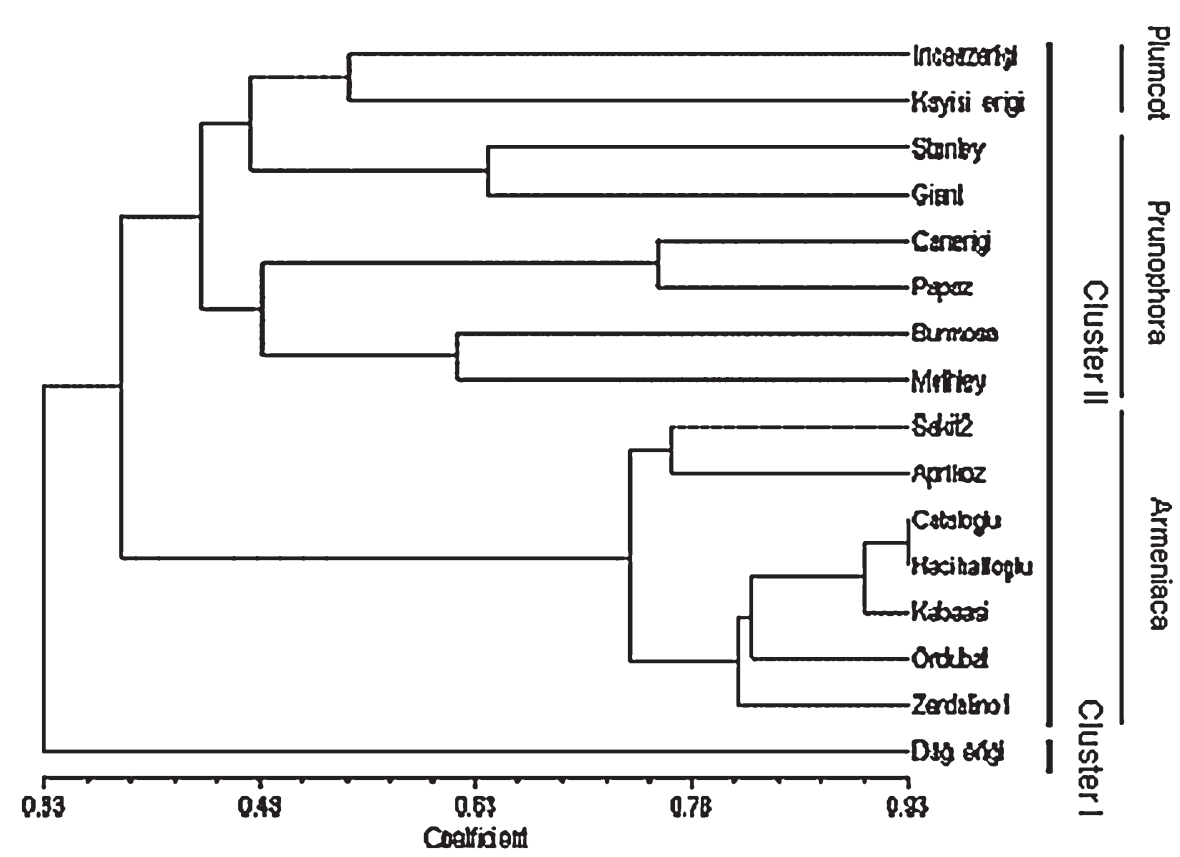

Fig. 1. Dendrogram of 16 genotypes from subgenus and sections in genus Prunus generated by 196 intersimple sequence repeat markers using unweighted pair group method with arithmetic mean cluster analysis based on the Jaccard coefficient.

Prunophora comprises three main plum species, namely diploid cherry plums (Prunus cerasifera cvs. Papaz and Canerigi), Japanese plums (Prunus salicina cvs. Burmosa and Methley), and hexaploid European plums (Prunus domestica cvs. Stanley and Giant). Interestingly, Cherry plum, Japanese plum, and European plum genotypes formed distinct single subclusters (Fig. 1). This could be resulting of different ploidy levels and origin of species. As well known, Prunus cerasifera and Prunus salicina had $2 \mathrm{x}$ and Prunus domestica 6x ploidy level. Despite some genomic similarities among diploid and hexaploid plum species, breeding barriers do exist among them. However, there are reports of successful introduction of genes from another wild diploid species into the Japanese plum, $P$. salicina, through interspecific hybridization and selection (Okie and Weinberger, 1996).

Subgroup Armeniaca was represented by six cultivars (Sakit 2, Aprikoz, Cataloglu, Hacihaliloglu, Kabaasi, and Ordubat) and one wild form (Zerdalino1) of apricot. The section Armeniaca considerably differentiated from the other section Prunophora and plumcots. This observation is further sup- ported by Watkins (1976), while discussing the evolutionary trends in the genus Prunus, suggested apricots to be farther from the center of the genus than plums. Turkish apricot cultivars belong to an Irano-Caucasian group and the main characteristics of this group is including mostly self-sterile smallfruited accessions (Mehlenbacher et al., 1990). Kostina (1969) reported that some level self-sterility also occurred in the Irano-Caucasian ecogeographic group, including Turkish cultivars. As mentioned before, the different levels of genetic diversity among apricot cultivars are much influenced by their self-(in)compatibility phenotype (Halasz et al., 2007b; Milatovic and Nikolic, 2007). In Turkey, it is very clear that apricot genotypes are also highly specific in their ecological requirements and consequently, commercial production is limited to some locations, where usually one or two cultivars account for most of the production (Ercisli, 2004; Guleryuz et al., 1999). The results obtained in this work suggest that apricot genotypes probably share a common genetic background and show a low degree of polymorphism. The idea is supported by Hormaza (2002) who conducted SSR analysis in a wide range of apricot germplasm.

There were interesting relationships among cultivars and wild form in the dendrogram related to apricot. The low chilling request table apricot cultivars, Sakit and Aprikoz, were found to be closer to each other than the other cultivars and wild form. The dried apricot cvs. Cataloglu, Hacihaliloglu, and Kabaasi were also found very close to each other. The white-flesh local apricot cultivar Ordubat had low fruit quality called wild form was to be close to wild apricot, Zerdalino1 (Fig. 1).

As regarding plumcot, two genotypes (cv. Inceaz erigi and cv. Kayisi erigi) formed a separate group within the section Prunophora. In other words, the plumcot genotypes 
Table 3. Jaccard's similarity coefficients of 16 genotypes from Prunus genus sampled from Turkey based on 196 intersimple sequence repeat fragments.

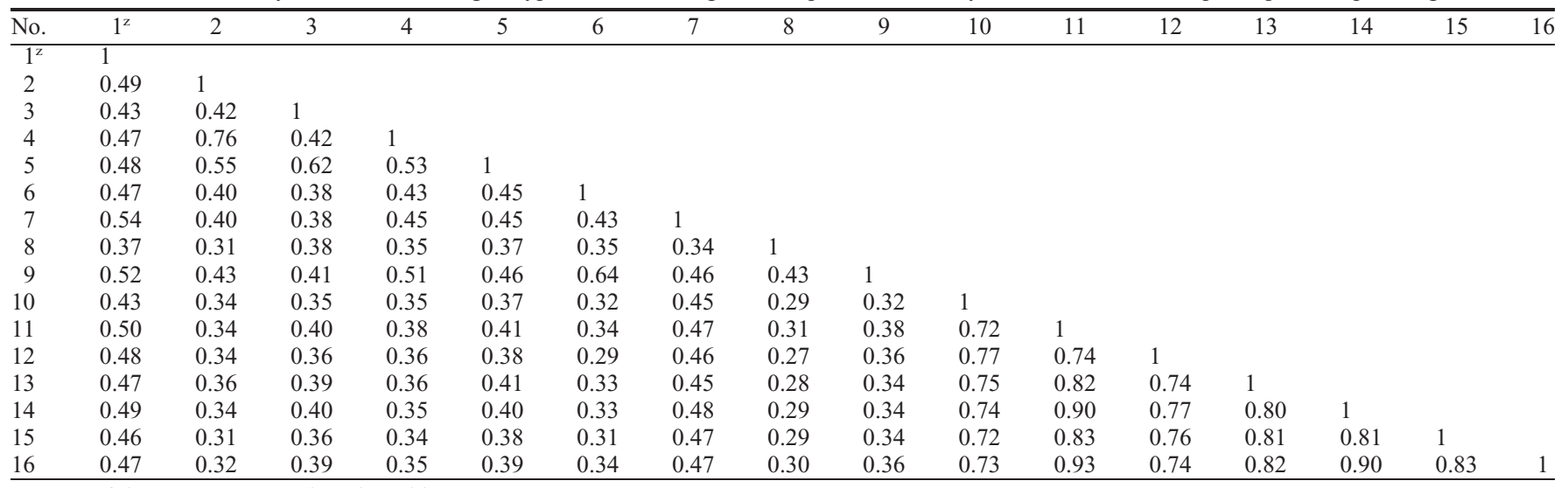

${ }^{\mathrm{z}}$ Names of the genotypes are given in Table 1 .

occupied the basal sister position to plum species within Prunophora. Previously, members of plum $\times$ apricot, based on their morphological characteristics, are considered to be closer to plums than to apricots in terms of leaf, seed, external color, flesh, and taste characteristics (Guleryuz and Ercisli, 1995). This suggests that the crosses could be resulting of open pollination of apricot with plum than backcrosses with plum of these hybrids. Mehlenbacher et al. (1990) reported that the cross is generally more successful when plum is used as the female parent and are useful sources of genes for late bloom. This could be explained by possible repeated backcrossing plum-apricot hybrids with plums. However, Liu et al. (2007) reported that hybrids of plum and apricot were more similar to apricot than the plum. The difference between the two studies could be explained by the used multiple male parents, which made their genetic background rather complex.

The pattern of differentiation among the genotypes within Prunus suggests four gene pools corresponding to the subgenera Prunus and Cerasus and also sections Prunophora and Armeniaca in Prunus subgenus, within which gene flow can potentially occur as interspecific hybrids within the same ploidy level are viable with the same levels of fertility.

Genetic similarities between genotypes were estimated using the Jaccard coefficient, and the similarity coefficient matrix was established in Table 3. The average Jaccard coefficients within and between sections and subgenera indicated that similarities within sections were higher than those between subgenera. The genetic variability was lower within Armeniaca genotypes than within Prunophora. The mean genetic similarity coefficient was 0.47 , indicating that genetic diversity among Prunus genotypes is high. The similarity values varied from 0.27 (Aprikoz-Zerdalino1) to 0.93 (Kabaasi-Dagerigi) (Table 3). The cophenetic correlation coefficient by Mantel test indicated a high correlation, $r=0.96$, between the similarity matrix and the UPGMA dendrogram. The cophenetic correlation coefficient is considered to be a very good representation of the data matrix in the dendrogram if it is 0.90 or greater (Romesburg, 1990)

Associations among subgenera and sections were also revealed by PCoA (Fig. 2). In the three-dimensional PCoA plot, in general, similar groupings with the UPGMA dendrogram and additional information were also revealed (e.g., the plumcots were placed between apricots and plums that reflect their phylogenenetic relationships). The first three principal axes accounted for $30 \%, 11 \%$, and $10 \%$ of the total variation, respectively, indicating the complex multidimensional nature of ISSR variation. The three-dimensional

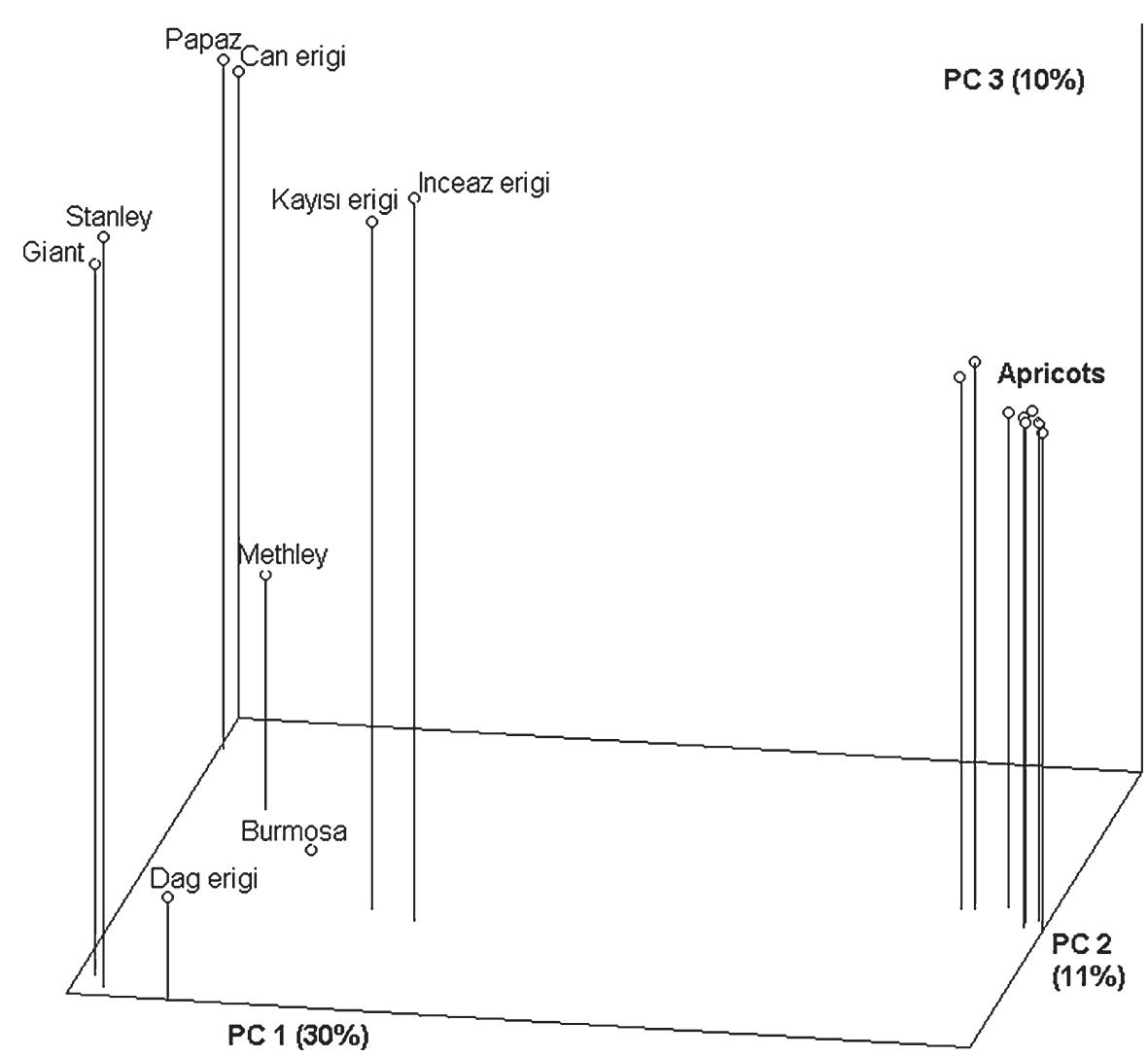

Fig. 2. Three-dimensional projection of intersimple sequence repeat variation calculated by principal coordinate analysis for 16 genotypes from Prunus genus. projection of genotypes along the first three principal axes revealed the overall genetic relationships among the subgenera and sections (Fig. 2). The two subgenera, Prunus and Cerasus, produced tight clusters and exhibited considerable divergence. The sections of Armeniaca and Prunophora and plum $\times$ apricot crosses also exhibited considerable divergence. Surprisingly, the first principal axis, which accounted for most variation $(30 \%)$, contributed the least to the separation of Prunophora. The factor loadings along the second axis $(11 \%)$ contributed to the separation Armeniaca from the remaining section. The third axis accounting for 
only $10 \%$ of the total variation was heavily loaded to discriminate the subgenera and sections Cerasus, Prunus, Prunophora, and Armeniaca. Cerasus and Prunus appeared to be the most divergent among the subgenera within the genus. According to Watkins (1976), members of the subgenus Cerasus were considered to be ancient and were the first to diverge from the ancestral Prunus. The two multivariate approaches, UPGMA and PCoA, used in the analysis of genetic relationships within and among the sections and subgenera of Prunus produced generally comparable results.

Nevertheless, PCoA is known to be less sensitive to distances between close neighbors but represents more accurately distances between clusters (Sneath and Sokal, 1973).

In conclusion, genotypes showed considerable differentiation along the sectional and subgeneric boundaries and allowed for some generalization on the genetic structure and differentiation within the genus Prunus by using the ISSRs. Evaluation of existing germplasm collections contributes tremendously to the understanding of overall patterns of distribution of genetic variation and allow for drawing some general conclusions. These results obtained by the ISSR analysis of Prunus genotypes may provide useful information for molecular identification, pedigree analysis, genetic improvement, germplasm conservation, and construction of core collections in Prunus.

\section{Literature Cited}

Aradhya, M.K., C. Weeks, and C.W. Simon. 2004 Molecular characterization of variability and relationships among seven cultivated and selected wild species of Prunus L. using amplified fragment length polymorphism. Sci. Hort. 103:131-144.

Bortiri, E., S. Oh, J. Jiang, S. Baggett, A. Granger, C. Weeks, M. Buckingham, D. Potter, and D.E. Parfitt. 2001. Phylogeny and systematics of Prunus (Rosaceae) as determined by sequence analysis of ITS and the chloroplast trnL-trnF spacer DNA. Syst. Bot. 26:797-807.

Cao, W., G. Scoles, P. Hucl, and R.N. Chibbar. 2000. Phylogenetic relationships of five morphological groups of hexaploid wheat (Triticum aestivum L. em Thell.) based on RAPD analysis. Genome 43:724-727.

Crane, M.B. and W.J.C. Lawrance. 1952. The genetics of garden plants. Macmillan, London, UK.

Doyle, J.J. and J.L. Doyle. 1987. A rapid isolation procedure for small quantities of fresh leaf tissue. Phytochem. Bull. 19:11-15.

Ercisli, S. 2004. A short review of the fruit germplasm resources of Turkey. Genet. Resources Crop Evol. 51:419-435.

Eryomine, G.V. 1991. New data on origin of Prunus domestica L. Acta Hort. 283:27-29.

Goulao, L., L. Monte-Corvo, and C.M. Oliveira. 2001. Phenetic characterization of plum cultivars by high multiplex ratio markers: Amplified fragment length polymorphism and inter-simple sequence repeats. J. Amer. Soc. Hort. Sci. 126:72-77.

Guleryuz, M. and S. Ercisli. 1995. Phenological and morphological investigation on apricot and plumcots in Erzincan. Proceedings of the 2nd National Horticultural Congress, Adana, 1995. 1:183-189.

Guleryuz, M., S. Ercisli, and A. Esitken. 1999. A study on characteristic features of apricot grown in Erzincan, Malatya and Iğdır provinces. Acta Hort. 488:165-170.

Halasz, J., A. Hegedus, Z. Szabó, J. Nyéki, and A. Pedryc. 2007a. DNA-based $S$-genotyping of Japanese plum and pluot cultivars to clarify incompatibility relationships. HortScience 42: 46-50.

Halasz, J., A. Pedryc, and A. Hegedus. 2007b. Origin and dissemination of the pollen-part mutated $S C$-haplotype that confers self-compatibility in apricot (Prunus armeniaca). New Phytol. 176 793-803.

Hormaza, J.I. 2002. Molecular characterization and similarity relationships among apricot (Prunus armeniaca L.) genotypes using simple sequence repeats. Theor. Appl. Genet. 104:321-328.

Kafkas, S., H. Ozkan, B.E. Ak, I. Acar, H.S. Atli, and S. Koyuncu. 2006. Detecting DNA polymorphism and genetic diversity in a wide pistachio germplasm: Comparison of AFLP ISSR and RAPD markers. J. Amer. Soc. Hort Sci. 131:522-529.

Kafkas, S., H. Ozkan, and M. Sutyemez. 2005. DNA polymorphism and assessment of genetic relationships in walnut genotypes based on AFLP and SAMPL markers. J. Amer. Soc Hort. Sci. 130:585-590.

Kostina, K.F. 1969. The use of varietal resources of apricots from breeding. Trudy Nikita Botanica Sada 40:45-63.

Lisek, A., M. Korbin, E. Rozpara, and E. Zueawicz. 2007. Plum cultivar DNA polymorphism generated with RAPD and ISSR markers. Acta Hort. 734:281-285.

Liu, W., D. Liu, A. Zhang, C. Feng, J. Yang, J. Yoon, and S. Li. 2007. Genetic diversity and phylogenetic relationships among plum germplasm resources in China assessed with intersimple sequence repeat markers. J. Amer. Soc. Hort. Sci. 132:619-628.

Maghuly, F., E.B. Fernandez, S.Z. Ruthner, A. Pedryc, and M. Laimer. 2005. Microsatellite variability in apricots (Prunus armeniaca L.) reflects their geographic origin and breeding history. Tree Genet. Genomes 1:151-165.

Mantel, N. 1967. The detection of disease clustering and a generalized regression approach. Cancer Res. 27:175-178.

Mehlenbacher, S.A., V. Cociu, and L.F. Hough. 1990. Apricots (Prunus). In: Moorem, J.N. and J.R. Ballington (eds.). Genetic resources of temperate fruit and nut crops. Acta Hort. 290: 65-107.

Milatovic, D. and D. Nikolic. 2007. Analysis of self-(in) compatibility in apricot cultivars using fluorescence microscopy. J. Hort. Sci. Biotechnol. 82:170-174.

Okie, W.R. and J.H. Weinberger. 1996. Plums, p. 559-607. In: Janick, J. and J.N. Moore (eds.) Fruit breeding, Volume I: Tree and tropical fruits. Wiley, New York, NY.

Prevost, A. and M.J. Wilkinson. 1999. A new system of comparing PCR primers applied to
ISSR fingerprinting of potato cultivars. Theor. Appl. Genet. 98:107-112.

Rafalski, J.A., J.M. Vogel, M. Morgante, W Powell, C. Andre, and S.V. Tingey. 1996. Generating and using DNA markers in plants, p. 75-134. In: Birren, B. and E. Lai (eds.) Nonmammalian genomic analysis. Academic Press, San Diego, CA.

Reddy, M.P., N. Sarla, and E.A. Siddiq. 2002. Inter simple sequence repeat (ISSR) polymorphism and its application in plant breeding. Euphytica 128:9-17.

Reynders, S. and G. Salesses. 1990. Study on the genetic relationships within the subgenus Prunophora. Restriction maps of the ribosoma genes in $P$. cerasifera and $P$. spinosa. Acta Hort. 283:13-26.

Rohlf, F.J. 2004. NTSYS-pc numerical taxonomy and multivariate analysis system. Version 2.11V. Exeter Software, Setauket, NY.

Romesburg, H.C. 1990. Cluster analysis for researchers. Krieger Publishing Company, Malabar, FL.

SAS Institute Inc. 1990. SAS users guide; SAS/ STAT, version 6. SAS Inst. Inc., Cary, NC.

Shahsavar, A.R., K. Izadpanah, E. Tafazoli, and B.E.S. Tabatabaei. 2007. Characterization of Citrus germplasm including unknown variants by inter-simple sequence repeat (ISSR) markers. Sci. Hort. 112:310-314.

Smith, J.S.C., E.C.L. Chin, H. Shu, O.S. Smith, S.J Wall, M.L. Senior, S.E. Mitchell, S. Kresovich, and J. Ziegle. 1997. An evaluation of the utility of SSR loci as molecular markers in maize (Zea mays L.): Comparisons with data from RFLPs and pedigree. Theor. Appl. Genet. 95:163173

Sneath, P.H.A. and R.R. Sokal. 1973. Numerical taxonomy: The principles and practice of numerical classification. Freeman, San Francisco, CA.

Swofford, D.L. 1998. PAUP: Phylogenetic analysis using parsimony (and other methods). Version 4. Sineauer Assoc., Sunderland, MA.

Terzopoulos, P.J., B. Kolano, P.J. Bebeli, P.J. Kaltsikes, and I. Metzidakis. 2005. Identification of Olea europaea L. cultivars using intersimple sequence repeat markers. Sci. Hort 105:45-51.

Vijayan, K. and S.N. Chatterjee. 2003. ISSR profiling of Indian cultivars of mulberry (Morus spp.) and its relevance to breeding programs. Euphytica 131:53-63

Vijayan, K., P.P. Srivatsava, C.V. Nair, A.K Awasthi, A. Tikader, B. Sreenivasa, and S.R. Urs. 2006a. Molecular characterization and identification of markers associated with yield traits in mulberry using ISSR markers. Plant Breed. 125:298-301.

Vijayan, K., A. Tikader, P.K. Kar, P.P. Srivatsava, A.K. Awasthi, K. Thangavelu, and B. Seratchandra. 2006b. Assessment of genetic relationships between wild and cultivated mulberry (Morus) species using PCR based markers. Genet Resources Crop Evol. 53:873-882.

Watkins, R. 1976. Cherry, plum, peach, apricot and almond, p. 242-247. In: Simmonds, N.W. (ed.). Evolution of crop plants. Longman, London, UK.

Zohary, D. 1992. Is the European plum, Prunus domestica L., a $P$. cerasifera Ehrh. $\times P$. spinosa L. allo-polyploid? Euphytica 60:75-77. 